\title{
Recognition, Redistribution, and Democracy: Dilemmas of Honneth's Critical Social Theory
}

\author{
Christopher F. Zurn
}

What does social justice require in contemporary societies? What are the requirements of social democracy? Who and where are the individuals and groups that can carry forward agendas for progressive social transformation? What are we to make of the so-called new social movements of the last thirty years? Is identity politics compatible with egalitarianism? Can cultural misrecognition and economic maldistribution be fought simultaneously? What of the heritage of Western Marxism is alive and dead? And how is current critical social theory to approach these and other questions?

Much of the most productive work done in recent social theory has revolved around such issues, in particular, around those concerning the relationship between the politics of recognition and the politics of distribution. After the intense theoretical focus over the last fifteen years or so on the issues of recognition politics-multiculturalism, multi-nationalism, identity politics, group-differentiated rights, the accommodation of difference, and so on-some social theorists have worried that attention has been diverted from important issues of distributive equality—systematic impoverishment, increasing material inequality, 'structural' unemployment, the growth of oligarchic power, global economic segmentation, and so on. While some critics seem to have adopted a blunt 'it's the economy, stupid' line of criticism, ${ }^{1}$ others have attempted to develop an overarching, integrative theoretical framework adequate to the diverse issues concerning both economic and cultural justice. For example, Axel Honneth proposes that a suitably developed and normatively robust theory of intersubjective recognition can adequately integrate an analysis of apparently diverse contemporary struggles: those for a just division of labor and hence, a fair distribution of resources and opportunities, as well as those for a culture free of identity-deforming disrespect and denigration. ${ }^{2}$

In two recent papers (Honneth 1998; 2001), Honneth appropriates John Dewey's political theory as a way of bridging the gap in critical, democratic theory between attention to economic struggles and struggles for recognition. And in a recent book exchanging views with Nancy Fraser, Honneth further develops his theory to show how everyday experiences of misrecognition can be understood as the normative and motivational well-springs of struggles against both economic and cultural injustices (Fraser and Honneth 2003a). I take it that the background motivation for these moves is to reanimate the critical thrust of the Marxist heritage of critical theory-namely, to ground a strong normative

European Journal of Philosophy 13:1 ISSN 0966-8373 pp. 89-126 (C) Blackwell Publishing Ltd. 2005. 9600 Garsington Road, Oxford OX4 2DQ, UK, and 350 Main Street, Malden, MA 02148, USA. 
critique of unjust relations of production and distribution-without the baggage of an empirically discredited labor theory of value, overextended hopes for a revolutionary proletariat class, or a dubious philosophy of history. The idea here is to find an alternative normative standpoint for the evaluation of contemporary economic relations that is tied to more universalizable - and hence justifiableclaims concerning deliberative democracy and the social bases of personal integrity. At the same time, the strategy insists on the distinctive social-theoretic claim of the Frankfurt School: that it can locate in actual, everyday life aspects of the same critical standpoint that the theory itself develops and relies upon. ${ }^{3}$ The strategy is thus to renew the critique of the distributive patterns of capitalism by means of a normative standpoint implicit in everyday experiences: reactions to violations of appropriate relations of intersubjective recognition.

In some ways, this appears to an American reader as a double return of the repressed: both for the history of critical theory and the development of Honneth's thought itself. At least since the dominance of Jürgen Habermas's theories of communicative action and deliberative democracy, interest in a critique of the relations of production seems to be confined to the history of theory, while issues of justice and morality, methodological rationality, formal legal and political relations, and cultural representation have occupied the forefront of debates. It can sometimes appear that the agenda of critical theory has been set more by the philosophical significance of questions than by their importance to achieving just social relations. ${ }^{4}$ So, a theory that holds out the hope of returning economic justice to the forefront of critical theory promises a return to traditional questions too long deferred.

That a focus on the division of labor may represent a return to a relatively occluded topic for Honneth as well is indicated by the contrast between some of his earlier and more recent work. For example, several of his early publications from around 1980 specifically address the extent to which Habermas's newly developed framework of communicative action can be used to address traditional Frankfurt School concerns about the protest and emancipatory potentials of class consciousness growing out of experiences of alienated labor. ${ }^{5}$ There Honneth argued that Habermas's categorical framework precluded access to working-class experiences and falsely presupposed that structural transformations had effectively deactivated class struggles. In contrast, Honneth sought ways to recover a pointed critique of the apparent success of the welfare-state compromise and its class structure.

In contrast to this earlier focus on the connection between class experiences and a capitalist division of labor, Honneth's more recent work from the 1990's has focused on the normative significance of new social movements, especially those that have centered around expanding extant relations of social recognition in the domains of the family, legal-political rights, and diverse ethical communities of shared values. ${ }^{6}$ Thus while, he has made suggestive comments about the relationship between the social division of labor and social structures of esteem (e.g., 1994: 266-267, and, 1995c: 88-91 and 146-151), the main focus of Honneth's work on recognition seemed more directly connected to the historical emergence

(C) Blackwell Publishing Ltd. 2005 
of identity politics and diverse attempts to reconfigure extant cultural and symbolic structures of valuation and interaction. It is only in his most recent work on Dewey and in response to criticisms from Nancy Fraser, that Honneth has now attempted to bring back to the fore issues of material distribution by systematically integrating them into an overarching theory of intersubjective recognition.

Of course, like any repression, there may have been good reasons for avoidance in the first place. In this paper I would like to explore some potential problems with this attempt to reinvigorate critical social theory's attention to economic injustices by means of a focus on the just division of labor required for individual self-realization. For instance, Honneth himself takes Marx to task for focusing exclusively on relations of production as the entirety of relations of mutual recognition in capitalist societies, and hence for reducing the diversity of recognition struggles to those over ownership of the means of production:

In his early writings, then, Marx narrows Hegel's model of the 'struggle for recognition' in the direction of an aesthetics of production. As a result, however, all aspects of intersubjective recognition that do not stem directly from the process of cooperative, self-managed labour get excluded from the moral spectrum of the social struggles occurring in Marx's day. (1995c: 148)

While I believe that Honneth's general theory of intersubjective recognition can successfully avoid the type of sociological dedifferentiation and consequent loss of diagnostic acumen he detected in the early work of Marx, I am concerned that analogous difficulties return in this recent proposal for integrating distributive concerns into a theory of recognition struggles. In particular, I am worried that the attempt to integrate a theory of distributive justice within the categorial framework of the theory of recognition-whether in the form of democratic, social justice, or critical social theories-risks either falsifying social reality or forgoing insightful practical guidance.

I begin in Section 1 by considering how Honneth proposes to broaden the claims of his original recognition theory (A) to encompass distributive injustices, both by appropriating John Dewey's theory of democratic cooperation and by developing a theory of social justice in terms of a society's cultural evaluation of various careers and accomplishments-its 'esteem dispositive' (B). After a brief consideration of the advantages of such an integration of distributive issues within recognition theory (C), I consider in Section 2 whether it rests on a sufficiently differentiated social theory. In particular, I look to Nancy Fraser's critique of Honneth's claim that a society's distributive arrangements should be conceived as the expression of that society's esteem dispositive, and then consider how Honneth might respond to the critique by moving to a high level of theoretical abstraction. Finally in Section 3 I argue that such an attempt to save the integration is caught in a theoretical quandary: employ a social theory that is either empirically accurate but too abstract for critical use, or one that is

(c) Blackwell Publishing Ltd. 2005 
normatively incisive but empirically deficient. Given that a critical social theory ought avoid claims that distort social reality, I conclude that Honneth's proposal to analyze and justify fair distributions in terms of the requirements of undistorted recognition cannot do the work it promises.

\section{Honneth's Democratic and Social Justice Proposals for Integrating Recognition and Distribution}

\section{A Honneth's Theory of Recognition}

Honneth's well-known theory of recognition intends to connect a theory of psychic development with a theory of social change in order to develop an account that is both empirically grounded in real experiences and normatively robust enough to critically evaluate contemporary social relations. ${ }^{7}$ Very briefly, his theory starts from an account of identity formation as an on-going, intersubjective process of struggling to gain mutual recognition from one's partners in interaction. Through this process of struggle, individuals develop three different forms of relation-to-self through three different types of social interaction: 1) self-confidence is gained in primary, affective relations, 2) self-respect in legal relations of rights, and 2) self-esteem in local communities defined by shared value orientations. ${ }^{8}$ These intersubjective processes of learning 'to view oneself, from the normative perspective of one's partners to interaction, as their social addressee' (1995c: 92) are the media through which individuals become who they are, and within which social forms of life are continually maintained and reproduced.

The first and most basic form of recognition is achieved in intimate relations of love and friendship, through which individuals are first able to achieve a measure of confidence in themselves as distinct from their environment and in the constancy of the world around them. To develop self-confidence in the stability of their own identity and the world, children need to be continually recognized and attended to in strong emotional relationships which provide a stable reality within which they can overcome their originally indistinct symbiotic relationships to primary others.

The second basic form of recognition is that achieved through the acknowledgment of one's formal capacity for autonomous moral action. Through the universal rights accorded to all members of a society, just insofar as they are members of that society, individuals are able to achieve self-respect for themselves as equals of other members, entitled to make their own decisions about how to conceive of and realize their own life plans. Thus, this second form of relation-to-self-self-respect-is realized through legal relations which recognize one as equally deserving of rights to negative liberty, access to political processes, and the burdens of legal responsibility.

The third form of recognition occurs through one's valued participation in and positive contributions to a shared way of life that expresses distinctive,

(c) Blackwell Publishing Ltd. 2005 
communally held values. In a group defined by social solidarity (usually a group smaller in size than the group of citizens as a whole in which self-respect is realized), one is able to achieve self-esteem by being recognized as a distinct individual, with particular traits and abilities that positively contribute to the shared projects of that solidaristic community. In modern societies, this third form of relation-to-self is separated-and must be separated-from the second form of self-respect. This is because, to be fair, legal relations must recognize in all citizens the abstract characteristics of moral autonomy, whereas, in esteeming a person, what is at issue is precisely that person's characteristic traits that are positively evaluated within a local community's shared horizon of values. Thus while self-confidence and self-esteem involve the understanding of oneself in one's concrete particularity, self-respect involves a relation to oneself in one's abstract universality.

Corresponding to the three positive forms of recognition, Honneth analyzes three forms of disrespect. At the most fundamental level, when one's control over one's own body-one's physical integrity-is violated by physical abuse, torture, rape, etc., then one looses trust in the stability of one's basic identity and constancy of one's world necessary for a healthy sense of self-confidence. Secondly, one's chance for developing moral self-respect can be negatively affected through the systematic denial of rights bestowed on other citizens. Finally, one's self-esteem can be undermined by the denigration and degradation of one's way of life, for in these cases one's way of life is not receiving the social esteem necessary for a healthy understanding of one's unique capacities and achievements.

Honneth then develops his critical theory through an account of the structural interconnection between a) the three levels of individual identity development, b) the three forms of intersubjective recognition required for each level, and c) the forms of social organization needed as preconditions for the healthy, undistorted self-realization of that society's members. This structural interconnection then provides a basis for explaining processes of social change-explicating both the impulse for expanded recognition and the normative claims raised in social struggles for individual and group recognition. For, when individual experiences of disrespect are understood as the norm for all members of a certain groupwhen disrespect is experienced epidemically - the potential motivation exists for collective political resistance to the structures of society which systematically deny the members of that group the recognition they need for full self-realization. And these struggles are normatively justifiable on the grounds that such systematic forms of disrespect impede the mutual recognition required for the maintenance and reproduction of healthy forms of self-relation and selfrealization. ${ }^{9}$

A salient strength of this internally differentiated and subtle account of intersubjective recognition is that it is particularly well-suited to analyzing not only those recent social movements that have demanded the recognition of group's specificity and difference, but also those movements that, for close to two hundred years, have insistently demanded an equal role in social affairs for those

(c) Blackwell Publishing Ltd. 2005 
formerly excluded on the basis of race, ethnicity, nationality, gender, physical ability, and so on. ${ }^{10}$ What Honneth now proposes to do, by incorporating Dewey's account of a democratic division of labor, is to extend this recognition theory to cover struggles over the just distribution of material rewards; in short, to comprehend class struggles as recognition struggles.

\section{B The Appropriation of Dewey's Democratic Theory}

In order to see how Honneth intends to comprehend distributive struggles within his recognition paradigm, we need first to see how he takes up Dewey's epistemic defense of democratic cooperation, and then uses it to justify calls for a democratic division of labor (Honneth 1998). The overt problem driving Honneth's appropriation of Dewey's theory of democracy is that of political participation. How should contemporary democratic theory explain the willingness of individual citizens to take an active part in social and political processes of collective opinion-and will-formation? A proper analysis of the motivational bases of participation should then point a way towards concrete recommendations for social restructurings that would encourage a more active citizenry. That political participation is a major problem for contemporary theory is determined by the intersection of both theoretical and empirical considerations. Theoretically, once the active involvement of ordinary citizens in political processes is conceived of as a normative requirement for the legitimate exercise of state power-as it is in prominent theories of deliberative democracy-the question arises of how and whether the concepts of democratic theory can have access to manifestations of this idealized demand for involvement in actually existing democracies. ${ }^{11} \mathrm{~A}$ defense of deliberative democracy is open to objections of empty utopianism if it has no conceptual resources for empirically discerning the existence of the legitimacy conditions it requires of politics.

Empirically, a number of features of our contemporary world seem, however, to speak against hopes for increasing citizen involvement in social and political processes. To begin with, one has to contend with social changes resulting from the disenchantment of sacred worldviews. Increases in value pluralism seem to constrict the domain of agreement between disparate citizens who endorse different value hierarchies, even as democratic participation seems to presuppose a great deal of pre-political agreement. ${ }^{12}$ Along with a loss of the 'sacred canopy' seems to come a loss of commitment to the public weal, as individuals retreat to privatistic pursuits and increasingly affirm the values of 'everyday life' ${ }^{13}$ Finally, accelerating individualization combines with value pluralism in the demands that each authentically realize their own unique way of life, often simply through distinction from any other extant way of life. ${ }^{14}$ In addition, attention must be paid to increases in social complexity which accompany the functional differentiation of spheres of social reproduction, whereby individuals in late capitalist societies find themselves increasingly faced by, and intermeshed in, quasi-autonomous

(c) Blackwell Publishing Ltd. 2005 
domains of action whose imperatives apparently operate independently of any substantive input from them. ${ }^{15}$ Compounding the participatory deficits that accompany this increase in social complexity, the state itself can often appear to be just another large, bureaucratically structured organization, as deaf to the pleas for change on behalf of suffering individuals as the codified legal system or the multinational corporation. ${ }^{16}$ Dewey's theory of democracy as a reflexive form of cooperation is ostensibly uniquely qualified to give a theoretically adequate and empirically sensitive account of the motivational bases of political participation, despite these countervailing forces.

According to Honneth's reading of Dewey, a theory of radical democracy should look to those pre-political associational communities-especially those connected with the world of work-within which individuals develop a sense of solidarity and an interest in solving collective social problems for the development and encouragement of participatory motivations. ${ }^{17}$ The leading idea here is that collective problem-solving in the context of social labor provides a paradigm for other collective activities, particularly political processes of opinion- and will-formation. Work contexts are exemplary learning environments for individuals as they experience the difficulties of cooperatively achieving shared goals. If social cooperation is to be possible and effective, individual problems must first be discovered as socially shared. Cooperating actors can then engage in needed deliberative and contestatory processes: setting goals for action, evaluating competing means for appropriateness, implementing those means through the allocation of specialized tasks according to ability and interest, and reflexively adjusting these processes in the light of experience. Furthermore, participants begin to understand that a wide diversity of group viewpoints, as well as increasing contacts with other groups and their approaches, actually increase the reasonability and rationality of solutions through enriching the context of deliberations. As Honneth puts it, in social cooperation ... the intelligence of the solution to emerging problems increases to the degree to which all those involved could, without constraint and with equal rights, exchange information and introduce reflections' (1998: 772-773). All of this contributes to both individual and collective learning concerning how social cooperation works best. ${ }^{18}$

Experiences of collective problem solving also provide contexts in which individuals can be recognized for their specific contributions and achievements. Such contexts constitute an important opportunity for developing healthy selfesteem. This opportunity, in turn, should be expected to motivate individuals to participate in broader socio-political decision making, beyond the confines of familial, affinity, and career groups, since they will have understood the social importance and personal benefits of contributing to broader associative activities. Dewey's resulting notion of democracy as a form of reflexive cooperation is therefore an expansive social ideal-an ideal of free and open cooperative associations between persons in a well-formed society-and not merely an ideal of recommended procedures for political decision making in the formal state apparatus.

(c) Blackwell Publishing Ltd. 2005 
Honneth is attracted to this ideal of democracy precisely because it is a social ideal, and as such, implies the need for certain social conditions to be met in order for it to be realized. In particular, because each member can only have an equal opportunity for realizing motivating social esteem in pre-political associations if there exists a just division of labor throughout society, Dewey's pragmatist analysis of shared problem-solving leads to a two-track justification for extensive, redistributive social rights. On the one hand, the motivational prerequisites for a democratic polity will only be fulfilled when all citizens can understand themselves as contributors to cooperative endeavors, and this requires a just distribution of labor. A pre-political sphere of cooperative activity in the world of work-provided it is based on a fair and just division of social labor-can furnish the learning environment for all citizens that will motivate them to grasp formal politics as another important context of cooperative activity requiring their input (Honneth 1998: 777). On the other hand, the general preconditions for the personal integrity of subjects' (Honneth 2001: 51)—those specified in a recognition theory of the universal requirements for a healthy form of social life-can also only be fulfilled equally for all subjects to the extent that there is a fair division of labor providing individuals the opportunity to develop healthy self-esteem through their contributions to collective problem-solving in general. In other words, a fair division of labor is justified on the one hand by the motivational requirements of political democracy, and on the other by the intersubjective requirements for undistorted identity formation. ${ }^{19}$

Of course, this latter justification for social rights should not be understood as exhaustive of the intersubjective requirements for personal integrity. As I have already indicated above, undistorted identity development also requires, at the least, an environment free from physical torture and forms of extreme emotional violence (for the development of self-confidence), a positive legal system granting individuals recognition as autonomous legal subjects (for the development of self-respect), and an environment free from the denigration of ways of life (for the development of self-esteem). One might consider Honneth's latest focus on the division of labor to be an elaboration of the requirements for an environment free from denigration in societies such as ours, where career accomplishments and remuneration loom so large in our evaluative considerations of individual worth. In sum, Dewey's theory of reflexive social cooperation generates justifications for an egalitarian division of labor in terms of both the motivational requirements for participatory democracy, and the social recognition structures necessary for the equal opportunity of each to develop an intact identity.

\section{The Advantages of Honneth's Integration}

Honneth himself emphasizes the advantages this theory of radical democracy has over competing theories of democracy, such as Habermas's proceduralist model and the republican models developed by Hannah Arendt and Michael

(c) Blackwell Publishing Ltd. 2005 
Sandel. For instance, the Deweyan paradigm gives both a clear, epistemic justification for democratic decision procedures, and a convincing explanation of the motivational well-springs of political participation. However, for my purposes, I am more interested in the advantages of the model from the perspective of a theory of the politics of recognition that does not occlude the politics of distribution, that is to say, from an integrative critical theory of social justice.

First, and in contrast to theories that stress the importance of recognizing commonality and achieving value consensus amongst all social members, the Deweyan ideal analyzes social diversity as functionally advantageous both for a society as a whole and its individuals. Since it is precisely a multiplicity of viewpoints and a division of labor which together allow for successful goal accomplishment, social diversity is not seen as disintegrative as it is in models which stress the need for a society-wide consensus on either the right or the good. The increasing pluralization and heterogeneity witnessed today should precisely contribute to the overall health of a society as it attempts to solve new problems. Furthermore, from the perspective of the individual, one can also see that belonging to a variety of reference groups is developmentally beneficial. As the number and variety of one's social memberships increase, the pressures for developing an integrated, post-conventional identity, which can coherently structure a number of potentially competing social role demands, also increase. This means that the social diversity manifested in a democratic community, with a just division of labor and relations of reciprocity and exchange between various political and non-political associations, encourages the development of autonomous citizens who can comprehend the worth of their contributions to social and political processes. ${ }^{20}$ Finally, the emphasis on a rich diversity of associational groups and on their overlapping and intersecting character mitigates against fetishizing one group identity to the exclusion of other possible identifications. Often in contemporary theories of recognition, there is an implicit prioritization of one identity-constitutive characteristic to the exclusion of all others, and this can lead to a politics that reifies one axis of groups differentiation and enforces an 'authentic', unquestionable identity for group members. ${ }^{21}$ The Deweyan model shows precisely how intra-group flexibility, group interaction, and multiple associational membership for individuals are all functionally advantageous.

The second main advantage of Honneth's Deweyan appropriation is that it enables his theory to strike a productive balance between the abstractions of ideal political theory and the potentially uncritical concreteness of descriptive endorsements of extant politics. On the one hand, the Deweyan model describes democracy as a rich social ideal, not just as a set of political arrangements: as a variety of associations engaged in reflexive problem-solving processes across diverse domains of life. This is in contrast to ideal political theory which must either invoke bridging non-ideal theories to connect up with sub-optimal political reality ${ }^{22}$ or leave the social preconditions of its political arrangements unspecified and at the disposition of contingent processes of political will-formation. ${ }^{23}$ On the other hand, the theory has a sufficiently independent set of normative criteria

(c) Blackwell Publishing Ltd. 2005 
that it is able to critically evaluate claims for expanded relations of recognition and for different divisions of labor. Republican theories, with their heavy emphasis on the development of the substantive virtues already endorsed by society, run the dangers of overburdening their theories with high ethical expectations for citizens and of shading into a provincialist celebration of a particularistic, often exclusionary, hierarchy of values. In short, Honneth's integration of his recognition theory and Dewey's theory of reflexive cooperation aims to give a better analysis of the social requirements for a democratic form of ethical life than competing theories; it can specify a democratic social ideal.

The final main advantage is that Honneth's Deweyan paradigm emphasizes the importance of greater economic equality for a healthy democracy in a way that competing theories do not. Because demands for a fair and just division of labor are justified by reference to the social conditions necessary for both democratic cooperation and opportunities to develop a substantive sense of self, distribution and recognition demands are systematically tied together. The crucial idea is to think of the extant distribution of remuneration across the division of labor in any society as an expression of current patterns of social esteem concerning individual task types, the abilities required to perform them, and their overall social contribution. Thus struggles over a fairer distribution of goods and resources should be thought of as recognition struggles. As Honneth puts the argument,

The rules organizing the distribution of material goods derive from the degree of social esteem enjoyed by social groups, in accordance with institutionalized hierarchies of value, or a normative order. ... Conflicts over distribution ... are always symbolic struggles over the legitimacy of the sociocultural dispositive that determines the value of activities, attributes, and contributions. ... In short, it is a struggle over the cultural definition of what it is that renders an activity socially necessary and valuable. (2001: 54)

This link between recognition and distribution is thus a way of directly justifying greater economic justice: distributive justice is a prerequisite for an equal opportunity for social esteem for all citizens, and this equal opportunity for esteem is required for productive democratic social cooperation and problemsolving. There is thus a direct justificatory link from democracy to substantive economic justice, in contrast to proceduralist theories of democracy where determining an appropriate level of economic equality is at the disposal of the vagaries of formal state politics, politics carried out within the contingent context of a specific legal and historical practice of constitutional specification (as in Habermas 1996: chapters 3 and 9). Unlike most theories of new social movements and the politics of recognition, however, Honneth's theory does not simply ignore demands for redistributive equality. ${ }^{24}$ And finally, a critical social theory that integrates recognition and distribution in this way can take up the mantle of Marxist demands for distributive justice without reference to a theory of

(C) Blackwell Publishing Ltd. 2005 
exploitation relying on a problematic labor theory of value, to an implausible philosophy of history, or to an extant and robust class movement already eager for a revolutionary restructuring of economic institutions.

\section{An Adequate Social Theory?}

However, it is precisely this tight link between recognition and distribution in Honneth's new integrative theory that Nancy Fraser argues against, and that I would now like to take up. To what extent might such a reduction of distributive arrangements to recognition structures overlook salient differences between various types of contemporary social struggles, and so risk flattening out important distinctions? To put the question in a different way, to what extent has the theoretical integration of Honneth's theory come at the expense of an oversimplified social theory? In this section I consider Fraser's critique of the sociological claims that underlie Honneth's program (A), and his responses to this critique (B).

\section{A Fraser's Sociological Critique of a Culturalist Reduction of Economic Relations}

Over the last several years Fraser has developed a 'bivalent' critical social theory that claims to be adequate to our contemporary 'postsocialist' condition. ${ }^{25}$ One feature of this condition, according to her, is an increasing differentiation at the level of political theory between the interpretive politics of recognition and the economic politics of distribution (1997c: 2-3). She aims to overcome this split by producing a conjoint theory of justice that can grasp both kinds of politics without, however, reducing one kind to the other.

Her theory starts by distinguishing between injustices of misrecognition and injustices of maldistribution by referring to their primary causal roots. ${ }^{26}$ Misrecognition is rooted primarily in cultural patterns of representation, interpretation, and communication, while maldistribution is rooted primarily in the political-economic structures of society. Misrecognition occurs when oppressive, exclusionary, disrespectful and/or denigrating cultural patterns of value are institutionally-anchored in such a way as to deny some the ability to participate in social relations on a par with others. Maldistribution occurs when economic mechanisms and structures deny some the material resources and opportunities they need in order to participate in social relations on a par with others.

Fraser is careful here to note a caveat: this distinction is not meant to suggest that misrecognition has no socio-economic effects or, conversely, that maldistribution has no cultural effects. Rather, the claim is that, since each form of injustice has different causal roots, different types of remedies are recommended prima facie: cultural and symbolic change one the one hand, political-economic restructuring on the other. Hence a politics of recognition is in general recommended to combat misrecognition causally rooted in evaluative patterns,

(C) Blackwell Publishing Ltd. 2005 
and a politics of redistribution is recommended to combat maldistribution causally rooted in systemic mechanisms of the political economy. The central problems for a critical social theory result, however, from the fact that the forms of subordination most major disadvantaged groups are subject to are twodimensional, resulting from both economic deprivation and distorting evaluative patterns. Such groups 'suffer both socioeconomic maldistribution and cultural misrecognition in forms where neither of these injustices is an indirect effect of the other, but where both are primary and co-original ${ }^{27}$ After closer investigation of the specific problems faced by collectivities defined by gender, race, class, and sexuality, she concludes that 'for practical purposes, then, virtually all real-world oppressed collectivities are bivalent' (Fraser 1998: 22).

In the light of this dualistic social analysis, a major task for critical theory then is to sensitively evaluate and propose various remedy strategies for overcoming the misrecognition and maldistribution subordinated groups simultaneously face. Remedy strategies that are oriented only to one of the axes of subordination will often fail by ignoring deleterious side-effects, unintended consequences, and/or negative feedback loops that may occur along the other axis. ${ }^{28}$ An adequate critical theory must then, according to Fraser, be sensitive to differences among the causes of injustice, the targets of remedy types, the kinds of subordination faced by groups, and the kinds of stratification evinced in society, in order to be able to comprehend the likely tensions and dilemmas faced in practical political action. ${ }^{29}$

What is compelling in Fraser's portrayal is her suggestion that we ought not reduce distributive injustices to recognition injustices, nor vice-versa, and that remedies appropriate for one kind of injustice will, in general, not be sufficient for the other. If she is correct in these claims, then Honneth's new paradigm for critical theory by means of Dewey's theory of radical democracy is in serious jeopardy. Honneth's justification of radical democracy relies on the relationship between a fair and just division of labor and the social conditions necessary for undistorted self-realization; in other words, it relies on the contention that recognition and redistribution injustices are systematically linked in a way that it makes little sense to distinguish them by the means of their causal origins. It claims, further, that remedies for maldistribution should be sought through transformations of extant recognition structures. I'd like to turn now to the arguments Fraser uses to support her dualistic social theory.

In her work from 1997 and 1998, Fraser simply assumed the theoretical propriety of distinguishing distributive and recognition injustices. The supporting argument there was largely implicit in showing the practical usefulness of a dualistic theory for revealing the character of the contemporary political scenewith recognition and distribution politics increasingly pursued in isolation from one another-and for highlighting the deeper reasons for the tensions faced by political strategies pursued with a single-axis focus. In an ongoing dialogue with Honneth's proposal to understand maldistribution in terms of misrecognition, however, Fraser has proposed some more direct socio-theoretic arguments for her anti-reductivist claims. ${ }^{30}$

(c) Blackwell Publishing Ltd. 2005 
Fraser proposes first a brief thought experiment to show how individuals may be harmed by one form of social injustice, where the harm is not a result of, nor reducible to, the other form of social injustice. Consider, for example, the harm suffered by an 'African-American Wall Street banker who cannot get a taxi to pick him up' (2001: 28). Here is a situation where the injustice results from patterns of symbolic value prevalent in American society that systematically code blacks as dangerous and untrustworthy. Yet, since he is a banker, he cannot have suffered the harm because of any characteristics tied to his class position or economic standing. Here it seems we have a misrecognition injustice independent of, and irreducible to, the distributive arrangements of society. In another case, consider the harm suffered by a 'skilled white male industrial worker who becomes unemployed due to a factory closing resulting from a speculative corporate merger' (2001: 29). Here the injustice results from economic imperatives of capitalist markets alone, as the status position of a skilled, white male worker is not one of general symbolic subordination or cultural devaluation. Hence the maldistribution is independent of, and irreducible to, misrecognition. From these two examples, we can see that the two kinds of harm can be independent of one another precisely because their causal origins are different and so, at the first level of analysis at least, should not be reduced to one another. ${ }^{31}$ Hence we need (at least) a dualistic social theory to properly analyze the extant (at least) dualistic structure of social subordination. ${ }^{32}$

A second kind of argument consists of straightforward citations of empirical phenomena that do not fit a model that reduces distributive injustices to injustices in underlying evaluative patterns. So, in contrast to the claim that wage labor rates and other schedules of compensation are fully determined by a society's esteem dispositive, Fraser points out that, in addition to cultural factors, remuneration rates are also dependent on evaluatively-independent

political-economic factors such as the supply of and demand for different types of labor; the balance of power between labor and capital; the stringency of social regulations, including the minimum wage; the availability and cost of productivity enhancing technologies; the ease with which firms can shift their operations to locations where wage rates are lower; the cost of credit; the terms of trade; and international currency exchange rates. (2003a: 215)

Consider further contemporary struggles focused on distributive issues, such as struggles against capital-driven forms of neo-liberalism and economic globalization. In these cases, what is at issue is not the esteem dispositive with respect to different forms of achievement within society, but rather the persistent structural inequalities generated by international networks of finance, trade, and production. In such cases, furthermore, changing extant evaluative patterns is simply not up to the task of overcoming the economic imperatives driving both the globalization and the impoverishment. The dislocations caused by global capital flows, and the global segmentation of enrichment and poverty generated by

(c) Blackwell Publishing Ltd. 2005 
international labor markets are not caused by distorted patterns of mutual recognition, nor can they be controlled or moderated by restructuring regnant esteem dispositives. Examples like these could be multiplied to show that, although some distributive struggles involve important issue of recognition, many-perhaps most-do not.

In the background here, of course, is a third kind of argument: an appeal to a general sociological theory distinguishing between different ways in which social institutions and arrangements are ordered in contemporary societies, and to an historical theory about the development of modern, capitalist societies. In particular, Fraser points out that the logic and dynamics of material-economic reproduction become increasingly independent of the logic and dynamics of cultural-symbolic reproduction under capitalism, and as a result of capitalist development itself. This is a familiar point from Adam Smith and Hegel forward. As Fraser puts it, societies are

complex fields that encompass not only cultural forms of social ordering but economic forms of ordering as well. ... Under capitalist conditions ... the economic dimension becomes relatively decoupled from the cultural dimension, as marketized arenas, in which strategic action predominates, are differentiated from non-marketized arenas, in which value-regulated interaction predominates. (Frazer 2000: 118) ${ }^{33}$

Since the action incentives follow different tendencies in the two domains of economy and culture, the reproductive processes that are institutionalized and generate patterned outcomes (social orderings) in each domain will tend to become independent of one another. So the third form of argument in support of her claim that recognition and distribution orders are mutually irreducible, is based on an historical account of capitalist modernization that portrays it as a process of the gradual decoupling of forms of system and social integration: 'capitalist society['s] ... distinguishing feature, after all, is its creation of a quasiobjective, anonymous, impersonal market order that follows a logic of its own' (Fraser 2003a: 214). Dualistic social theory tracks what are, in fact, definitive results of the socio-historical development of modern capitalist societies.

The fourth form of argument is practical: an adequate analysis of contemporary political problems can only responsibly evaluate the various options open by attending to the complexity of contemporary society. Such an analysis helps us illuminate the concrete potentials and problems faced in praxis today, by strategizing in an integrative way. If in fact there are (at least) two different causal origins of social injustice in contemporary society, corresponding to two different forms of injustice and two different axes of stratification, then it makes no sense from the point of view of a critical social theory to reduce one to another, as this may lead us to support ineffective remedies aimed at the wrong causal roots of various injustices. Even worse would be recommending remedies aimed at one form of injustice that actually compound injustices in another form. Witness the misrecognition backlash occurring from many mainstream policies of social

(C) Blackwell Publishing Ltd. 2005 
welfare redistributions: paltry public aid to impoverished families is stigmatized as handouts to lazy 'welfare queens'. ${ }^{34}$ Just as distributive remedies can have unintended recognition effects, recognition-focused remedies may exacerbate economic injustice. Witness the deleterious labor market effects of attempts to overcome denigration of African-American culture through the adoption of an 'Afro-centric' educational curriculum: job applicants culturally-coded as black in the job market are systematically economically disadvantaged. The anti-racist and feminist movements are neither exclusively cultural nor economic, as suggested in some everyday imaginaries, but are aimed simultaneously at two different roots of injustice. If critical theory hopes to at least theoretically clarify the various options available for political action aimed at overcoming social injustice, then it must depend on a social theory robust enough to analyze the major structural and dynamic principles of contemporary societies, in both their distinctions and interconnections. In complex, differentiated societies, according to Fraser's argument, there is no choice but to have a correspondingly complex and differentiated social theory.

It is important to remember again Fraser's claim that there may be-and indeed usually are-interconnections and interdependencies between these two dimensions of social ordering. Thus economic injustices may be compounded by persistent patterns of cultural denigration, and misrecognition harms may be increased by economic deprivations. In fact such interrelations and interactions can only be adequately analyzed if we start from a social theory that recognizes the socio-theoretic distinction: there is no way of accounting for the particular 'mix' of economic and cultural factors if we do not acknowledge that there is a ' $m i x$ ' in the first place. According to Fraser, insight into the actual interimbrication of maldistributive and misrecognitional mechanisms evinced in contemporary society requires us to keep them theoretically distinct.

\section{B Honneth's Rejoinders}

Fraser's distinctions between economic and cultural dimensions of social reproduction and between maldistribution injustices and misrecognition injustices appears to be a convincing repudiation of Honneth's strategy for conceiving of the division of labor as the result of a social esteem dispositive, at least with respect to its socio-theoretic assumptions. He has, however, briefly responded to Fraser's critical arguments in three ways (2001: 52-55). First he claims that Fraser relies on an improper and misleading chronology-one suggested by Charles Taylor's overly-stylized history of social movements-that portrays struggles for legal and material equality as the old movements, and struggles for the assertion of cultural identity as the new movements. ${ }^{35}$ Against this, Honneth argues both that identity politics is not a new phenomenonwitness the struggles for women's suffrage, for the end of race-based chattel slavery, for national self-determination, and against colonial domination-and that struggles for material equality have always had a recognition component-

(c) Blackwell Publishing Ltd. 2005 
witness the attempts to redefine and ennoble the culture and traditions of manual labor. Here I think Honneth is correct to insist that an accurate historical account of social movements of the last 200 years would resist easy dualistic chronologies that pit old material and legal politics against new cultural politics. However, this would only affect Fraser's critique of a culturalist reduction of redistributive politics if in fact that critique were based on such historical assumptions or claims. I think it is clear that her account is not so dependent. Indeed, the only major historical assumption of her argument is that there has been, in modern developed societies, a differentiation of mechanisms of social reproduction between markets and value systems. Her argument is not, in the main, historically based, but based in sociological claims about contemporary societies. An attack on Taylor's alleged historical simplifications is simply immaterial to her critique.

Buried in Honneth's argument, however, is a second response to Fraser's critique. This is the claim that the variety of types of recognition struggles cannot be reduced simply to the one form of an identity politics of difference. According to Honneth's tripartite account of struggles for recognition, in fact, we should be able to understand variety of struggles-for legal equality, for political participation, for a pluralistic and tolerant culture, for overcoming exclusionary xenophobia, for a non-violent private sphere-as all aimed, in different ways and through different media, at expanding relations of reciprocal recognition. ${ }^{36}$ In Fraser's simplified account of Honneth's position, 'the struggle for recognition comes to be ... reduced to the single aspect of cultural recognition so that all other dimensions of the struggle for recognition remain ignored' (2001: 53). ${ }^{37}$ This seems to me an important corrective to a reading of Honneth's work-one Fraser at points relies on-that is too willing to see it only through the prism of contemporary social movements that aim at the socio-cultural recognition of distinct cultural identities and demand group-differentiated treatment on the basis of such claims. ${ }^{38}$ This is, in short, to confuse Honneth's broad theory of recognition with a narrow politics of group authenticity. However, even though Fraser does misread Honneth in this way, Honneth's rejoinder still does not directly address her claim that critical social theory must be (at least) dualistic. Acknowledging that recognition politics may be more varied than the politics of identity does not yet require that we conceive of distributive mechanisms as reducible to evaluative patterns, maldistributions to misrecognitions, or demands for socio-economic justice to demands for socio-cultural justice.

Honneth's third response is the only one that seems probative vis-à-vis Fraser's critique. He argues that, at a sufficient level of abstraction, we should conceive of the rules of material allocation in any society as determined by that society's comparative evaluation of different ways of contributing to social reproduction and the attributes necessary for doing so. Criticizing Marx's attention only to wage labor and the relations of production evident in the formal economy, Honneth points out that feminist scholarship has highlighted how crucial childrearing and housework is to the reproduction of society. Along these lines, we could understand, for instance, struggles for the social provision of

(c) Blackwell Publishing Ltd. 2005 
adequate day care or for the remuneration of housework as, in fact, struggles over the degree to which such activities and their necessary qualifications are to be socially esteemed. In this way, distributive struggles can be understood as recognition struggles. As Honneth puts it, 'rules of distribution cannot simply be derived from the relations of production, but are rather to be seen as the institutional expression of a sociocultural dispositive that determines in what esteem particular activities are held at a specific point in time' (2001: 54). If Honneth is right that, for instance, market dynamics can be conceived of as the results of institutionalized recognition relations, then Fraser is wrong to claim that distribution and recognition are irreducible.

At a very high level of abstraction, of course, Honneth is correct. For no capitalist economy is possible apart from those legal relations that secure private property, enforce the actionability of contracts, establish the legality of commodity markets for some entities but not others, establish the parameters of employability, protect against fraud and deceit, regulate labor contracts, establish fair procedures for bargaining between firms and employees, and so on. And in constitutional democracies these legal relations might in turn be conceptualized as the expression of socially-shared evaluations of the comparative worth of different tasks, and by extension, those who have the ability and determination to carry them out. At this high level of theory we could, in other words, reduce economic relations to a socially-shared esteem dispositive by means of legal relations. ${ }^{39}$ The question is whether it would be useful to do so.

\section{Dilemmas of Abstractive Integration}

The productivity of Honneth's abstractive integration of recognition and distribution can best be judged, I think, in relation to the theoretical purposes it is intended to serve. In the following section I consider the usefulness of this strategy from the perspective of three theoretical concerns: from the perspective of a theory of radical democracy oriented to participatory motivations (A), from that of a theory of social justice oriented to maldistribution (B), and, from that of a Frankfurt School-inspired critical social theory oriented to connecting everyday experiences to a social theory with normative intent $(C)$. In each case, I will argue that Honneth's integrative theory faces a generality/concretion dilemma: either adopt an empirically accurate but theoretically useless abstract social theory, or adopt a theoretically productive but empirically inaccurate concrete social theory.

\section{A Democratic Theory}

I believe such a dilemma befalls Honneth's attempt to link recognition and distribution for the purposes of a democratic theory oriented to participation. Recall that he develops this aspect of his theory through an appropriation of

(C) Blackwell Publishing Ltd. 2005 
Dewey's account of reflexive cooperative activity. In short, the theory intends to justify a fair economic distribution as a functional requirement of democracy, by means of the motivational benefits for formal politics of esteem-generating work within a fair division of labor. The general tasks of such a democratic theory would then include analyzing the social preconditions for radical democracy, evaluating proposed transformations of extant social conditions, and justifying preferred remedies. Yet, in carrying out these tasks, I contend, Honneth's theory faces a generality/concretion dilemma.

To justify a fair economic distribution in terms of the functional preconditions of democracy, the theory must focus on the world of work as the only site for the development of participation-motivating self-esteem through cooperative activity. For if functionally equivalent sites were found, there would be no justificatory inference from the requirements for democratic legitimacy to a just distribution. But claiming functional irreplaceability for work experiences would evidently ignore alternative potential sites for such democracy-reinforcing identity development. The history of twentieth century theories of the intersubjective basis for self-realization alone is sufficient to point out this variety. Consider the diversity of domains that different social theorists consider as privileged for the development of authentic self-realization: the world of work for Marx, Lukács, early Heidegger and Dewey; political participation for Arendt and Habermas; substantive value communities for Charles Taylor and Bernard Williams; intimate reference persons (the family) for psychoanalysis and object-relations feminism; social roles for Mead and Parsons; and so on. Consider further the multiplicity of forms of association that individuals may find as meaningful social contexts for the realization of their concrete individuality: nuclear and extended families, workplaces, organized religions, cultural and educational associations, voluntary and civic associations, racial and ethnic affinity groups, subcultural enclaves, on-line communities, and so on. Given this variety of social domains and of forms of association potentially well-suited for developing participation-motivating self-esteem, it seems that the world of work is not functionally irreplaceable for the legitimacy and efficaciousness of formal democratic processes. Even less so does this one domain appear functionally irreplaceable for that broader democratization of all relations of social cooperation which Honneth and Dewey endorse. It is true that Dewey's ideal of democracy as a form of reflexive cooperation does show why we need a rich, diverse, and vibrant civil society as the motivational and educational bases for legitimate and effective political democracy. ${ }^{40}$ But if there is a large variety of associational fora-beyond only the world of remunerated workwhere individuals can realize motivating self-esteem and learn through cooperative problem-solving, then such a justification cannot show, in addition, that we need that just division of labor that would give rise to a more fair distribution of economic resources and opportunities. In other words, the argument from democracy to a fair distribution seems to turn on the reduction of all forms and domains of cooperative activity to those contained in the world of paid labor.

(c) Blackwell Publishing Ltd. 2005 
Honneth's potential responses to this objection would force his theory into a dilemma between theoretically productive empirical falsehoods and theoretically ineffective abstract truths. On the one hand, he might simply insist that a person's experience in the work world alone is sufficient to supply the motivational wellsprings and cooperative learning environments that are functionally required by deliberative democracy. Here the normative task of a justification for redistribution would be saved at the cost of the empirical accuracy of the social theory. Such a move would evidently overlook the variety of identity-constitutive and participation reinforcing domains of social life, while tenaciously hanging on to an empirically false claim about the irreplaceability of the world of remunerated work. In addition, such a move would force the theory to conceptualize all struggles for recognition over the social bases of self-esteem into the mold of a struggle over the division of labor. Thus Honneth's insightful tri-partite distinction between types of recognition struggles would be forced, apparently, to portray any struggle against the denigration of a way of life or a collectively-shared worldview as ultimately a struggle over the extant evaluative dispositive concerning the social usefulness of labor. However, this seems a manifestly incorrect way to think about, for instance, queer struggles against the denigration of non-heterosexual sexualities and sexual identities. In short, this strategy for saving the normative claim by insisting on reducing diverse esteem-generating contexts to the world of work leads to an empirically distorting sociological theory, and threatens the analytic insights of Honneth's original recognition theory.

On the other hand, the theory might look to save the justification for a fair distribution through abstraction. It could insist that all of the various social domains and associational fora pointed to above can be understood, at a suitably high level of abstraction, as parts of the overall division of labor. The idea here would be to conceive all of the social activities that might form a medium for the development of self-esteem as socially-useful labor, so that the call for a just division of labor requires more than a transformation of the workplace, scales of remuneration, and the set structures of careers. Rather, such a call for a division of labor that could sustain democratic processes would apply to any and every domain where social cooperation creates potential conditions for the development of self-esteem, solidarity, and problem-solving capacities. The attractiveness of some expansion of the category of labor comes across when we think about, for instance, traditionally defined 'women's work' which falls outside the remunerative division of labor but is clearly socially irreplaceable activity. We should worry about the almost unlimited expansion of the category of labor comprehended here however. For, with such a redefinition, we seem to enter into a sociologically undifferentiated night in which all cows are gray. In so expanding the category of labor to cover all social venues for esteem development, the theory looses the critical capacity to comparatively evaluate different associational fora and different social domains of cooperation for their potential helpfulness in achieving the goals of reflexive democracy and distributive justice. For instance, bowling leagues, reading groups, neighborhood crime watch groups, micro-loan cooperatives, and factory floors may all equally provide

(c) Blackwell Publishing Ltd. 2005 
opportunities for self-development in the context of social cooperation, and so be counted as aspects of the division of labor that contribute equally to democratic participation. Nevertheless, I would expect important differences between them, not only with respect to their likely functional contributions to deliberative democracy, but more importantly with respect to their likely efficaciousness in transforming maldistributions into just distributions. It is precisely this kind of practical, strategic insight that is foreclosed, however, by the move to a level of abstraction high enough to be empirically accurate.

This quandary means that Honneth's democratic theory is forced to decide between an empirically shortsighted justification for tightly linking recognition and redistribution, or an adequately differentiated theory that gives up the linkage by acknowledging the distinct dynamics of the division of labor and social relations of recognition. It is clear, as Dewey and Honneth stress, that effective deliberative democracy - whether in the arenas of formal governance or in the wider spheres of social interaction generally-requires some substantial levels of willingness to participate on the part of a broad and diverse elements of a society. However, an exclusive focus on the world of work and a just division of labor runs the risk of foreclosing access to alternative fora and avenues for individual development that can provide such social prerequisites for democracy. Self-realization through labor should be seen as only one possible-but not privileged-locus for the development of self-esteem, and of the motivations required for democratic participation. ${ }^{41}$ But if labor is only one such forum among many, then Honneth cannot make the strong justificatory case for a fair material distribution by means of the social requirements for undistorted relations of recognition. The dilemma of an integrative theory in this case is that it must choose, apparently, between an empirically accurate and sociologically insightful theory that forgoes the proposed recognition-based justification for redistribution, and a strong justificatory theory possible only through empirical distortions and sociological blind spots.

\section{B Theory of Social Justice}

Turning now to a social theory oriented toward diagnosing and overcoming the increase of material inequalities throughout and across societies, Honneth claims that particular distributive patterns should be conceived as the outcome of a society's esteem dispositive. Given a recognition-based analysis of the causes of economic injustice, a theory of social justice should be able to justify calls for a fairer distribution as a normative requirement following from the principle 'that each member of a democratic society must have the chance to be socially esteemed for his or her individual achievements' (2001: 53). ${ }^{42}$ Furthermore, such a theory should also be able to give practical guidance to social movement participants by evaluating the potential efficacy of various proposed remedies for maldistribution. By considering some examples, we may be able to gauge the usefulness of such a theory.

(C) Blackwell Publishing Ltd. 2005 
A paradigmatic example for Honneth appears to be feminist struggles to expand the definition of socially useful labor beyond that occurring in the formal labor market. Here a recognition-based analysis of one of the main causes of women's comparative impoverishment seems apropos, since the main reason reproductive 'women's work' is unpaid, even though socially essential, appears to be a deeply entrenched esteem dispositive encoding androcentric values and interpretations. In addition, Honneth's critical social theory is clearly able to justify claims for changing this dispositive-and so changing its resultant distributive patterns-in terms of the social requirements for egalitarian individual self-realization. Finally, the theory is also well suited to showing why at least some potential remedies are not recommended. Thus, programs for an immediate legal mandate requiring remuneration for all reproductive labor, without a substantial cultural change, would likely be not merely ineffective but positively regressive by means of strong backlashes. Also, remedies oriented at restructuring the wage labor market would miss the real causal target: namely, the extant institutionalized hierarchies of value concerning socially useful work.

Honneth's integrated theory also seems appropriate to legal remedies such as those aimed at overcoming discrimination against the physically and mentally disabled in the labor market, such as that effected by the landmark Americans with Disabilities Act. ${ }^{43}$ Here such a theory could show the causal roots of maldistribution in terms of a pattern of misrecognition of traits and abilities, show the efficacy of formal legal remedies given the experience of previously successful anti-discrimination legislation, and justify such remedies in terms of the social conditions all persons need to ensure an equal opportunity for full selfrealization.

Such an analysis seems causally misguided, however, when considering Fraser's example of white male industrial worker who was laid off because of a speculative corporate merger. Since he is not a victim of any form of identitybased disrespect or status subordination by hypothesis, the injustice is better attributed to the structure of unconstrained market mechanisms. Furthermore, the theory's strategic guidance, oriented in general towards changing patterns of value and interpretation, would operate at such a high level of abstraction that it could not usefully differentiate between proposed legal, political, economic, or socio-cultural remedies. Finally, given that the worker has not suffered a recognition injustice, it would be strange to justify calls for change in terms of his and all persons' needs for a social environment conducive to personal integrity.

Consider also the recent upsurge in struggles for a so-called 'living wage' especially among workers in the unstable and usually unbenefited sector of service industries. The economic problems highlighted in such struggles seem not so much to hinge on an extant hierarchy of evaluations concerning the social usefulness of service labor, or the traits and abilities of service workers themselves. Rather, one significant root of the problem is political geography, in particular, the relative mobility of labor purchasers in comparison with the immobility of laborers and of political authority. In the United States, for instance,

(c) Blackwell Publishing Ltd. 2005 
struggles for a living wage are usually defeated by the unwillingness of local and state electorates to trade increased social justice for decreased capital investment, especially given the threat potential posed by the ease of movement of capital to another state or locality. Similar problems encountered across European countries are part of the reason for adopting an integrated economic-regulatory landscape across the EU, even as it is an open question whether this simply pushes the structural tensions outwards from national to Union boundaries. In any case, because such distributive injustices are not directly causally rooted in a given esteem dispositive, a normative justification of struggles for a living wage in terms of the social conditions of personal integrity seems beside the point. Finally, any strategic guidance possible from Honneth's theory will be at such a high level of remove as to be uninformative at best.

Honneth might respond to these problematic examples in one of two ways. On the one hand, he might try the abstractive move. So, he might insist that labor dislocations due to speculation or to capital mobility can ultimately be traced back to an esteem dispositive that has given rise, through the democratic enactment of law, to the relative autonomy of market relations from legal, cultural, and political restraints. Then he would be able to justify calls for change directly in terms of the social conditions of recognition required for undistorted individual development. But the theory would loose the analytic perspicacity into the causal origins of the dislocations that is ultimately required for any useful strategic or practical guidance to social movements, since the theory would be unable to distinguish meaningfully between legal, political, cultural, or economic causes and remedy strategies. On the other hand, he could attempt a move towards concretion. In this case, the idea might be to retain a fine-grained socio-theoretic account by insisting that distributive injustices which appear to be the result of autonomous logics of the law, the marketplace, or electoral politics, are all in fact the direct effects of social hierarchies of esteem concerning tasks, traits, and abilities. Here, theoretical insight is bought at the cost of evident empirical inaccuracy.

In short, Honneth's rejoinder to Fraser's critique-to derive distributive patterns from the recognition dispositive at a relatively high level of abstraction-is caught in a dilemma of integration. It either must retreat to a high level of abstraction in order to save the empirical phenomena under the recognition analysis, or it must descend to a sufficiently substantive level of social analysis in order to provide strategic guidance. However, in the former case, it looses requisite socio-theoretic insight, while in the latter case its cedes empirical accuracy. Another way to put this dilemma is that it is one between normatively productive but strategically impotent oversimplifications, and, strategically promising but empirically inaccurate distortions. I conclude that a theory of social justice attempting to draw a tight connection between the development of self-esteem through intersubjective recognition and a just division of labor is caught in a generality/concretion dilemma: risk effacing significant empirical differences amongst the causes and potential remedies for maldistribution, or risk significantly misrepresenting that empirical reality.

(c) Blackwell Publishing Ltd. 2005 


\section{Critical Social Theory}

In the more extended back-and-forth between Fraser and Honneth in their new book, Honneth has significantly enriched and expanded his previous sociotheoretic conception of how a given society's division of labor is determined by its esteem dispositive. Here he is particularly concerned to show that only his recognition-theoretic integration can claim to fulfill the strong requirements set by the left-Hegelian legacy worked up in the Frankfurt School and continued by various theorists since. The main desideratum, as Honneth sees it, is that a critical social theory must be able to find significant elements of its social theory, its normative justifications, and its practical recommendations mirrored within everyday, extant social reality. The basic idea is that critical social theory must be able to identify some morally-laden feelings or expectations experienced by social actors that point towards a transcendence of current, pathological forms of social order. The critical social theorist needs such a point of reference for the critique of society that is simultaneously extant in social reality, morally structured, concerned with the social character of life, and, capable of pointing beyond the present social formation to a better form of life. In short, this is the idea that a critical analysis of society needs to be tied to an innerworldy instance of transcendence' (2003a: 238).

For Honneth, this methodological requirement gets redeemed through his integrative recognition-based critical social theory. Starting with a phenomenology of experiences of moral dismay, it must be able to then interpret such everyday experiences as the result of the denial of one or more of the forms of mutual recognition necessary for the development of an intact identity, reconstruct the context-transcending force of moral claims to recognition, connect these claims with an historical theory of social development by showing that apparently diverse struggles for social justice are best understood in terms of the realization of recognition principles, and finally normatively justify both the objectives of progressive social struggles and, reflexively, the grounds of its own theoretical point of view. Needless to say, this is an ambitious theoretical agenda. What is of import here is that the demand for an especially tight correspondence between everyday moral experiences and the categories and claims of social theory motivates a search for a way to connect the moral components of recognition theory both to the everyday moral feelings of social actors and to the relatively anonymous, functional processes that generate systemic economic inequalities, seemingly behind the backs of social actors. If the independence of economic processes from normative constraints is only apparent, and social actors' experiences of being disrespected can be shown to be connected to maldistributive mechanisms, then a fully critical social theory could be developed on the basis of a theory of recognition alone-conflicts over redistribution could be conceived of as conflicts over recognition.

Honneth's socio-theoretic argument for such a conception starts with the claim that market mechanisms themselves presuppose forms of normative legitimacy. Capitalist markets depend on the acceptance, by a society's members, of the

(c) Blackwell Publishing Ltd. 2005 
moral legitimacy of some irreplaceable preconditions: the legal system that establishes and regulates private property, corporations, the transaction medium of money, markets, and so on; the compensation schemas of interpretation that match specific normative interpretations of what counts as work and esteemworthy achievement to remunerative scales; and, the complex set of reciprocal behavioral expectations and habits of interaction that make possible necessary social networks, relations of intersubjective trust, and stable relations of authority (2003b: 135-150, and, 2003a: 250-256). Honneth might also have mentioned here the legitimacy dimension involved in the market prerequisite of properly socialized individuals who have internalized behavioral controls that prevent them from engaging in covert but egregious relations of coercion and fraud, even when it may be strategically beneficial to do so, thereby keeping enforcement costs reasonable. In short, according to Honneth, if there were not these various normatively-laden prerequisites, market mechanisms could not work. Furthermore the general acceptance of these prerequisites is capable of being withdrawn at any time if social members feel sufficiently violated by the structures and outcomes of market mediated relations (2003a: 255).

Generalizing from his recognition theory, Honneth then posits that any particular society's social order is constituted by its context-specific interpretation and institutionalization of the three basic moral principles of reciprocal recognition: the unconditional claim for love and care of each as an embodied, vulnerable, and emotional individual (enabling the development of selfconfidence), the equal legal equality of each as an autonomous person (enabling the development of self-respect), and the merited appreciation of each according to her or his achievements (enabling the development of self-esteem). Accordingly, the normative expectations expressed in the prerequisites of capitalism should be conceived of as realizations of two of these three basic moral principles of recognition: legal equality and individual accomplishment. ${ }^{44} \mathrm{~A}$ specific social order can be grasped, in general then, as a-usually incomplete and defectiverealization of these basic moral principles; a society's social order is determined by its recognition dispositive. But because market relations, the division of labor, and the distributive outcomes of both, are all elements of the social order, they too are determined by this recognition dispositive: distribution is determined by recognition. Hence any distributive injustices in a society should be grasped as forms of misrecognition, and any struggles against them grasped as challenges for a more expansive realization of the socially-implicit moral principles of recognition.

Most of the evidence Honneth cites for these socio-theoretic claims are examples of how, in a capitalist society, distributive outcomes are determined by that society's specific realization of the equality and accomplishment principles. Today's distributive patterns should be seen as the results of past conflicts over both the degree of social rights needed to guarantee full legal equality, and over what is to count as productive labor, and how highly it is to be valued, for each to be recognized for her or his achievement: 'When they do not take the form of mobilizing social rights, redistribution struggles are definitional conflicts over the

(c) Blackwell Publishing Ltd. 2005 
legitimacy of the current application of the achievement principle' (2003b: 154). Honneth again points here to his paradigm example of feminist struggles over the definition and comparative evaluation of household labor and care work to show the normatively-laden character of market structures and mechanisms. He claims that it is precisely a cultural dispositive that grades women's work as worthless that can explain the lower wages of traditionally female-occupied jobs in the formal labor market, and explain the loss of status that occurs to a career once it is culturally coded as feminine (2003b: 152-155). He also again points to the recognition elements evident in historical workers movements and class struggles: 'After all, the labour movement ... was in important ways directed at the aim of gaining recognition for people's own traditions and ways of life, within the ambit of capitalist values' (2001: 53; see also 2003b: 131). He also claims that, since feelings of disrespect in general are the motivations underlying all social conflicts, there is a basic recognition element to any social struggle; even those that may appear superficially to be 'merely economic' have a cultural dimension (2003b: 157). This can be seen in the way that, for instance, proposals for deregulation are usually protested against in the name of a loss of rights, that is, a loss of adequate social conditions of recognition. 'Indeed, the term "deregulation" itself is a direct indication of the fact that the labor market is organized by legal norms that express the moral interests of those involved' (2003a: 254). Furthermore, the basic medium of markets-money-itself must have some degree of-always revocable-social belief in its legitimacy if it is to function as an exchange medium (2003a: 255-256). Finally, even if a functionally integrated subsystem of economic action has separated out from those spheres of social interaction that are directly normatively regulated, this 'uncoupling' is only possible through legal norms and beliefs in legitimacy which both instantiate normative principles (2003a: 255-256).

What are we to make of these strikingly broad and strong claims? To begin with, there is a conspicuous ambiguity in Honneth's actual formulations, one that centers on words such as 'determines' and 'determinants': do they mean 'dictates' - as the sole or overwhelmingly significant causal factor-or do they mean 'influences' - as one among several significant factors? On the one hand, Honneth appears to be making the strong claim that normatively-laden interpretations of the equality and accomplishment principles of recognition dictate ('determine') the division of labor and its attendant compensation schedules. On the other hand, he repeatedly retreats from such a strong claim, moving rather to the weaker and more general claim that legal and evaluative aspects of recognition are but one variable among others in influencing or constraining economic processes and outcomes. Consider two remarkably opposed passages: 'Definitional patterns and evaluative schemas, deeply rooted in the culture of bourgeois-capitalist society, determine not only which of the various spheres of activity and action performances in general are to count as "work" and so are open to being an occupation, but also the current degree of social return for each occupational sphere of activity'. ${ }^{45}$ Yet in his rejoinder to Fraser, Honneth denies that his theory of recognition operates as an explanatory account of the

(C) Blackwell Publishing Ltd. 2005 
underlying causes of market dynamics. 'I do not wish to be understood as a representative of the cultural turn in the social sciences, nor did I want to make any claims about the determinants of market occurrences themselves, nor do I think an analysis of globalizing capitalism could be adequate if it ignored considerations of corporate profitability and utilization' ${ }^{46}$

One interpretation of the second, weaker line of argument evident in the latter passage is that, in response to Fraser's criticisms, Honneth revises his conception of the relation between recognition structures and economic processes. In a move quite reminiscent of Habermas's distinction between the rationally-reconstructible logic of historical social development and its contingent dynamics (Habermas 1979), Honneth claims that there are normative constraints, in the form of the demands for legitimate social interaction, upon functionally integrated domains of life. Although functional forms of integration may follow their own dynamical laws, laws that cannot be reduced to the logic of mutual recognition, functionally-integrated spheres of sociality are nevertheless limited by the normative infrastructure-the moral grammar-of the underlying recognition order.

My concept of a 'recognition order', which ... aims at this stratum-the epoch-specific grammar of social justice and injustice ... is, of course, not sufficient to explain the dynamics of developmental processes in contemporary capitalism. But it is meant only to make clear the normative constraints embedded in such processes.... I continue to assume that even structural transformations in the economic sphere are not independent of the normative expectations of those affected, but depend at least on their tacit consent. (Honneth 2003a: 250)

In short, according to this set of claims, recognition structures are not the sole or even significant determining cause of immediate, short-term distributive outcomes, but are merely the pacemakers-as general structural constraintsof large-scale, long-term changes in the political economy.

We seem to have, therefore, an ambiguity concerning how to interpret Honneth's 'determines': between a stronger and a weaker version of the set of claims concerning the causal dependence of distributions upon extant patterns of recognition. I think that this ambiguity is not accidental, but results from an oscillation between opposing sides of the generality/concretion dilemma I have been identifying throughout Honneth's integrative social theory, and I believe it gives rise to the same set of unattractive theoretical alternatives: incisive but overly-concrete, and so reality-falsifying claims, or, empirically accurate but overly general, and so uninsightful claims.

If we understand the recognition-distribution relationship in a strong sense, then Honneth can fulfill the left-Hegelian desideratum: he can clearly show the correspondences between the point of immanent transcendence in everyday experiences of economic disrespect and denigration, and the normative and socio-theoretic points of immanent transcendence at the level of theoretic

(c) Blackwell Publishing Ltd. 2005 
analysis. The starting experiential claim is surely correct: when individuals lose their job to 'downsizing', or take a pay cut in order to maintain a job, or cannot find rewarding work in a stagnant job market, or have inadequate resources for gaining the new cultural capital needed for employment in a changing division of labor, they do experience these as affronts to their sense-of-self, affronts generated by a seemingly distorted or inadequate appreciation of their own worth and achievements. Building on a moral phenomenology of such maldistributive harms, Honneth then endeavors to show that the harm is best conceived in terms of a normative analysis of violated expectations of legitimate intersubjective recognition. Finally the socio-theoretic claim is made that the harm has been caused in one of two ways: either the principle of legal equality has been inadequately realized in a deficient system of social rights, or, the principle of individual achievement has been inadequately realized in a distorting definitional and evaluative career schema. Hence the theory is able to detect everyday deformations that can be normatively justified and linked to an explanation of their causes, all in terms of the theory of recognition. If true, furthermore, this line of argument could fulfill another desideratum of critical social theory in reciprocally linking theory back to practice. It would be able to give a determinate analysis of the likelihood of success of various proposed reform strategies and so give relatively precise praxis guidance to social actors: when labor market participants experience dislocations, they should endeavor both to secure an adequate provision of legally-secured social rights and to culturally transform deficient interpretive schemas of achievement.

When we turn to examples, however, the socio-theoretic aspects of these claims seem less plausible. Consider the recent phenomenon of wide-spread and multi-pronged protests against the structures and symbols of capitalist globalization. As Honneth claims, it is quite likely that the multiple and often conflicting underlying motivations for such protests-jingoistic unease with the loss of nation-state sovereignty, universalist protest against the inegalitarian consequences of capital mobility both within and across nation-state boundaries, outrage at the environmental degradation fueled by globalization, unhappiness with the ineffectiveness and/or complicity of official political representatives and state apparatuses, even self-interested dismay at direct personal harms, etc.could be systematically reconstructed in terms of the recognition framework. It may well be, further, that a sufficiently differentiated account of legitimate intersubjective norms of recognition may be able to sort justified from unjustified claims amidst the welter of motivations for these protests. However, it is unlikely that insufficient realizations of recognition principles are actually the single-or even a directly relevant-cause of the economic dislocations whose effects are registered in the protests. The causes of the dislocations are to be found, rather, in variables specific to the political-economy: global currency rates, globally disproportionate supply and demand, asymmetrical regulatory environments, global capital flows, stratified distributions of productivity-enhancing technologies, differential natural resource distributions, national and international interest rates, differential regimes of private property, and so on.

(C) Blackwell Publishing Ltd. 2005 
Consider alternatively, another globalization phenomenon arising from the fact that national borders are less and less important to multi-national corporations shopping on the job market: skilled white-collar jobs requiring a great degree of specialized professional training are being increasingly outsourced from the United States, Canada, and Europe, to Southeast Asia and India. Here we seem to have a pretty clear example of careers enjoying high esteem-not just customer service, but personnel relations, payroll, computer programming, business-to-business sales, product development, and so onwhere, nevertheless, many workers face downward spiraling wage pressures, if not outright unemployment. Harmed workers may feel that they are being disrespected and their achievements denigrated, and we may be able to evaluate whether in fact these feelings point to instances of injustice in terms of a robust normative analysis of legitimate recognition expectations. However, again, the evident explanation for the cause of these changes in the global division of labor and the remuneration schedules has little to do with changing recognition relations. It is rather, that when choosing between paying a programmer $\$ 120,000$ and $\$ 20,000$ per year, market imperatives simply dictate the 'choice'. In such a case, it is implausible to claim that society's recognition dispositives determine either the division of labor or the degree of social return (the wage rate) accruing to different occupations. Moreover, counseling specifically recognition remedies may compound the harms: any increases in one locality's social rights schedule or labor market regulation may cause employers to shop elsewhere entirely. Likewise, attempts to reinterpret androcentric value patterns that contribute to the sex-gap in earnings may induce employers to seek more patriarchal and traditional societies where the impoverishment of women can be exploited.

It is precisely the theory's methodological insistence that everyday experiences of injustice must actually track the sociological mechanisms generating those harms that leads to empirical distortions which, in turn, may well mislead struggles for distributive justice. I trust that the same examples adduced abovewhere neither the division of labor nor the schedule of compensation actually track a society's recognition dispositive-and the extensive list of causal variables adduced by Fraser (2003a: 214-215) as involved in determining labor market dynamics - most of which are directly related only to market mechanisms-are sufficient to falsify this more concrete interpretation of the argument from an underlying recognition dispositive to market dynamics. Honneth is surely right about how most distributive harms are experienced by individuals, but accurate social insight and practical guidance need more than insistence upon the leftHegelian theory desideratum of the Frankfurt School; they need a social theory that does not falsify social reality.

If we don't want to sacrifice empirical accuracy, then we might turn to Honneth's weaker version of the claim: a society's recognition structures have $a$ determining influence in its division of labor and remuneration scales, but autochthonous economic mechanisms also play a large role. At a general level, according to this version, culture is one significant variable in the historical development of capitalist markets, since many of a capitalist market's functional

(c) Blackwell Publishing Ltd. 2005 
prerequisites (law, private property, reciprocal behavioral expectations, habits, trust, authority, socialized individuals) and central elements (money, restricted markets, compensation schemas) can only have the functional roles they do to the extent that they are acknowledged as legitimate by social actors, that is, to the extent that such prerequisites and elements accord with the underlying normative grammar of legitimate intersubjective relations of mutual recognition. Hence at a general level, capitalist markets could never have developed as relatively independent, functionally-integrated domains of social action without citizens' basic recognition of such prerequisites and elements as at least endurably acceptable. Thus culture functions as a structural constraint upon the economy, even as the latter exhibits its own internal dynamics (Honneth 2003a: 256). Notably, this position is not that different from Fraser's sociotheoretic account, where cultural and economic forms of social ordering are analyzed as dynamically distinct but nevertheless with causal interrelations.

Here, both Honneth and Fraser are surely correct to emphasize, against purely economistic models (such as pure rational-choice models), that the structure and dynamics of market processes, especially labor market processes, cannot be analyzed in isolation from regnant interpretive patterns and evaluative schemas. The problem for Honneth is that, in accepting the empirical accuracy of this weaker multi-variable approach, he has to give up the tight connection between pre-theoretic experiences of dislocation and the socio-theoretic explanation of their causes, as well as the reciprocal link from theory back to practice in the form of strategic guidance. For now the theory does not have the requisite tools for sorting out which of the many variables is actually involved in specific patterns of maldistribution, dislocation, or exploitation. Since the weaker theory does not attempt to explain market dynamics or processes, but only highlight their multivariant character, it cannot point out which of the possible 'determinants' is most important in any particular example or pattern of maldistribution. This means that such a critical social theory would be, at best, uninsightful in comparing various proposed remedy strategies for social struggles or, at worst, positively deleterious in its practical guidance, as negative feedback relations between recognition and distribution mechanisms generate injuries out of attempted remedies for insult. An (at least) bivalent social theory would seem to promise better action guidance given the (at least) bivalent character of the multiple variables involved in distributive injustices. An overly-general appeal to the theory of recognition may both be empirically accurate and satisfy the leftHegelian desideratum of linking everyday practice to theory, but it will not be able to link that theory back to practical struggles for justice, precisely because of its generality.

\section{Conclusion}

An understanding of critical theory as an interdisciplinary social theory with normative intent, one that is sensitive to 'the struggles and wishes of the age,'

(c) Blackwell Publishing Ltd. 2005 
implies certain criteria of adequacy, a central one of which, at the least, is the nondistortion of social reality. The same criterion applies equally to theories of democracy or of social justice, especially when they make substantive claims about causes and potential remedies of democratic exclusions or inegalitarian outcomes. Given that such theories ought to avoid inaccuracies, it seems that Honneth's proposed integration of recognition and redistribution must fall short in its ambitions. For in all three cases, it must choose between empirically false but promising justificatory claims, and, accurate but analytically empty justificatory abstractions. But this is, in a sense, no choice at all. If the only way to retain the justificatory inference from recognition to distribution is to move to such a high level of abstraction that the theory can no longer fulfill the requisite tasks of insightful social analysis and pertinent remedy evaluation, then this strategy for integration should be abandoned. This recommendation is further supported by the dedifferentiating effect the proposed integration appears to have, reflexively, for the originally capacious account of recognition: by reducing the variety of esteem-based recognition struggles to those over the division of labor, and the variety of respect-based recognition struggles to those over social welfare rights, the integrative theory looses some of the perspicacity of Honneth's earlier theory. Perhaps a suitably capacious, internally differentiated normative theory of recognition can be combined with a suitably accurate, differentiated, and multi-valent theory of social ordering. ${ }^{47}$ Though this combined strategy would surrender the strong speculative claim that both everyday experiences and the structure of social reality can be understood in the same terms, it would still have the basic ingredients of a powerful critical social theory: normative justificatory power, empirical and analytic perspicacity with respect to social reality, and significant praxis-guiding insight. In short, I recommend that Honneth combine his phenomenological and normative theories of recognition, with a socio-historic theory of capitalist modernization not confined to the categorial framework of recognition.

To return to comments I made at the beginning about the historical trajectory of Honneth's work, this latest theory might be seen as a slightly pathological mode of return for the important but temporarily repressed topic of distributive justice. Recall Honneth's account of Marx's turn away from healthy theoretical development: Marx's drive towards socio-theoretic parsimony led to distortions in his theory's normative account of the full spectrum of social struggles. Ironically, we might see the developmental difficulties of Honneth's theory as simply the converse of Marx's: a drive towards normative parsimony has led to socio-theoretic distortions. For it is precisely the promise of a tidy integration at the level of normative justifications that provides the theoretical motivation for appropriating Dewey's account of a just division of labor in a democratic society, for conceiving of distributive struggles as securing the requisite social conditions for an intact identity, and for identifying everyday experiences of distributive injustice as resulting from a society's specific realization of recognition principles. This normative parsimony, however, leads in this case to sociological simplifications and distortions.

(c) Blackwell Publishing Ltd. 2005 
I am not suggesting that Honneth relinquish the tasks of analyzing the seriously inegalitarian distributive arrangements extant in contemporary societies, nor that he abandon the quest for a theory that can insightfully evaluate the options available for remedying maldistributions. In fact, both of these tasks seem ever more urgent given recent trends towards neo-liberalism in the Western world and the intensified globalization of markets that are less and less capable of being restrained by national-state policies. I am suggesting, however, that attempting to reduce the socio-theoretic dimensions of distributive questions to those of recognition issues is not a promising route for coming to terms with the diversity of forms of contemporary injustice. The quest for parsimony can drive theory into generality/concretion dilemmas, and force a choice between empirically accurate integrations performed at a level too abstract for practical guidance, or, normatively and practically incisive integrations performed at a level of concretion that surrenders verisimilitude. What we would ultimately like is a theory that is both socio-theoretically astute and normatively integrated, for then we could confidently generate the normative and critical analyses required to promote and guide struggles for increased social justice of all types. In the case of struggles for recognition, redistribution, and democratization, this may, however, only be possible in the short term through the development of different theoretical tools appropriate to different social phenomena. ${ }^{48}$

Christopher F. Zurn

Philosophy Department

1415 Patterson Office Tower

University of Kentucky

Lexington, KY 40506-0027

USA

cfzurn@uky.edu

\section{NOTES}

${ }^{1}$ See, for example, the broad polemics in Gitlin 1995.

2 At least two other broad theoretical alternatives are also apparent in the literature. On the one hand there are attempts to develop an overarching theory of distributive justice that is also sensitive to the harms of misrecognition. For instance Rawls 1999 conceives of the social bases of self-respect (often thought of as a matter of recognition) as a good that can be distributed. Such a moves are the converse of Honneth's proposal to bring distributive issues under the aegis of recognition: in Rawls's paradigm, misrecognition is treated as a form of maldistribution, while in Honneth's, maldistribution is treated as a form of misrecognition. Rather than either form of reductivism, there is also the possibility of developing a 'bivalent' theory of social justice, one that keeps the social analysis of distributive arrangements distinct from that of recognition arrangements, intending only to bring them under the broad aegis of a multi-pronged theory of justice. Nancy Fraser's work is the leading representative of such a bivalent approach: see, for example Fraser

(C) Blackwell Publishing Ltd. 2005 
1997d; 1998; 2001; Fraser and Honneth 2003b. Citations to Fraser's work from this latest, co-authored book are to the English versions of her chapters: 2003a; 2003b.

3 This is a formulation of the task Honneth understands as distinctive of the Frankfurt School style of critical social theory. See Honneth 1994: 256 and 2003a: 238-247.

${ }^{4}$ One such critique of Habermas's theoretical agenda for being insufficiently attentive to social justice understood as distributive equality can be found in Marsh 1995.

${ }^{5}$ See Honneth 1979; Honneth 1995d (originally published in 1980), Honneth 1995b, (originally 1981) and, Honneth 1995a (originally 1982).

6 The central work in this period is Honneth 1995c. Further clarification can be found in Honneth 1992, 1994, 1996.

7 The account of Honneth's recognition theory presented in this sub-section recapitulates the main theses of Honneth 1995c.

${ }^{8}$ It is important to note here that these three terms-self-confidence, self-respect and self-esteem-serve as technical terms for Honneth, and their meaning is not always the same as our everyday usage of them would indicate. While Honneth's notion of selfconfidence tracks psychoanalytic discussions about the infant's differentiation from significant others and the achievements of individuation, his notions of self-respect and self-esteem track the philosophical discussion of the distinction between universal moral respect and particularistic evaluative esteem.

9 I reconstruct and critique the trans-contextual normative aspirations of Honneth's theory of recognition in Zurn 2000. In this paper, I presuppose, arguendo, the soundness of that normative theory within the specific context of developed post-industrial constitutional democracies.

${ }^{10}$ In Zurn 1997 I try to show how Honneth's tri-partite recognition schema is very useful for analyzing recent social movements concerning identity. In particular, I argue there that apparently antithetical political impulses behind universalist and difference feminism are in fact better understood as complimentary political impulses aimed at different kinds of social structures of recognition that are necessary for the healthy development of different aspects of individual identity. I extend this argument to the tensions between so-called 'normalizing' and 'queer' tendencies in recent debates over sexuality and sexual identity in Zurn 2004.

${ }^{11}$ A good overview of some of the idealized themes of deliberative democratic theory, arguing that they can in fact be subject to falsification by empirical reality, can be found in Bohman 1998.

12 Rawls's famous solution to what he calls 'the fact or reasonable pluralism' is to suggest that there can be an overlapping consensus on a limited domain of practical reasons (i.e., 'public reason'), and that political cooperation is possible on the basis of this uncontroversial core of values. See Rawls 1996. However, because Rawls's solution employs a set of gag rules intended to restrict the content of public discussions, it is antithetical to fully participatory and deliberative models of democracy.

${ }^{13}$ Charles Taylor has developed a sensitive account of the historical specificity of what he calls 'the affirmation of everyday life' in Taylor 1989.

14 Taylor 1992a points out the perils of the, admittedly dominant, individualistic and privatistic interpretations of the ideals of authenticity. For an astute account of the philosophical and historical rise of demands for individual autonomy understood (or perhaps misunderstood) as authenticity, see Habermas 1992.

15 One version of this thesis that increasing social complexity has deleterious consequences for citizen participation is Habermas's thesis of a colonization of the lifeworld by systemic imperatives. See, for instance, section VIII of Habermas 1987.

(C) Blackwell Publishing Ltd. 2005 
16 Weber's account of the iron cage of modernity is, of course, one version of this social diagnosis. See, for example, the selections from Economy and Society on bureaucracy in chapter VIII of Weber 1946.

17 Honneth's account of Dewey's theory of democracy draws largely on Dewey 1984, but he also draws widely on all periods of Dewey's work. I am not interested here in the extent to which this is an accurate representation of Dewey's mature theory, but in the positive doctrines that Honneth tries to distill out of this work.

18 The connections between a democratic form of associative life, the division of labor, and the educative value of cooperative activity are continually emphasized in Dewey 1980, especially chapter VII.

${ }^{19}$ Honneth points out this two-track justification of social rights follows from the Deweyan conception of democracy as reflexive coordination at Honneth 2001: 53. I return to these two justificatory tracks of democracy and social identity, as well as a third concerning Honneth's intention of taking up the methodological tasks of the Frankfurt School, below in Section 3.

${ }^{20}$ Dewey never tired of making this point by comparing the individual in a gang of thieves-who after all must engage in some cooperative behavior and hence learn through collective problem-solving - with the individual who must develop a consistent structure of roles and behaviors across her memberships in diverse and overlapping associations. See, for instance Dewey 1984: 327-328, and, 1980: 87-89.

21 As just one example, Taylor 1992b endorses group-differentiated rights of cultural survival for Francophones in Canada, without apparently considering either the potentially homogenizing effects of an intra-group enforcement of 'authentic' Francophone identity or the multiple identity-constitutive memberships French speakers can have that might conflict with their Francophone interests. Fraser 2000 and Fraser 2001 both contain powerful critiques of the potential reifications of such models of recognition politics. However, I think Fraser's ascription of such an authenticity model of recognition to Honneth is misplaced, as I argue in Zurn 2003b.

${ }^{22} \mathrm{I}$ am thinking here of the rather baroque theoretical structure concerning the interrelations between ideal theory and so-called 'non-ideal' theory adumbrated in Rawls 1999: 215-220.

${ }^{23}$ I am thinking here of the theory of social rights put forward in Habermas 1996. In particular, Habermas's commitment to strict normative universality leaves his proceduralist theory unable to spell out the required social conditions and ethos for radical democracy, beyond simply noting that democratic institutions require an antecedent commitment to political participation somehow embedded in 'accommodating' political cultures and personality structures. This is a point made at Honneth 1998: 779-780.

${ }^{24}$ This criticism of recognition theories as occluding redistributive justice has been a persistent theme of Nancy Fraser's work since the mid 1990's. See, for example, Fraser 1997a, 1998, 2003a, 2003b.

${ }^{25}$ See especially Fraser 1995, 1997a, 1997b, 1997c, 1998, 2000, 2001.

${ }^{26}$ My account of Fraser's bivalent theory follows that given in Fraser 1997a, 1998, 2003b. As will become clear below, the distinction between misrecognition and maldistribution is introduced as analytically useful in these essays, and, rather than argue for it through the marshalling of extensive sociological evidence, Fraser marshals a (relatively implicit) theoretical argument relying on the degree to which the distinction usefully highlights the contemporary political and theoretical scenes.

27 Fraser 1998: 15, emphasis original. In her updated version of the Tanner lectures, she changes the label from 'bivalent' to 'two-dimensional' collectivities, Fraser 2003b: 19.

(C) Blackwell Publishing Ltd. 2005 
28 A subtle analysis of the differences between three approaches to distributive equality-equal opportunity for welfare, resource equality, and capabilities equality-can be found in Olson 2001. Olson gives a convincing argument in favor of a capabilities approach to equality on the grounds, prepared by Fraser, that such a distributive politics best mitigates against creating misrecognition harms through stigmatizing backlash.

29 Although in her earlier work, Fraser claimed that there is a chronic dilemma between recognition and redistribution struggles (see especially Fraser 1997a), she has more recently abandoned this strong thesis in favor of the more realistic claim that there is a multitude of practical tensions, trade-offs, and interferences between various types of remedy strategies (see especially Fraser 2003a, 2003b). Critical evaluation of the earlier thesis can be found in Zurn 2004.

${ }^{30}$ Fraser also has arguments against Honneth's proposed reduction from the point of view of normative theory. I am less convinced by these, in part because I believe Fraser conflates Honneth's theory of recognition with other theories, while misconstruing many of his theoretical strategies for normative justification. I address some of these concerns in my critical evaluations of Fraser's latest attempt to think about recognition independently of considerations about identity in Zurn 2003b, and of her development of a deontological theory of participatory parity in Zurn 2003a. In this article, I focus on socio-theoretic concerns, attempting to leave normative issues to the side (to the extent possible).

${ }^{31}$ Fraser deepens this argument through another thought experiment distinguishing between a society entirely ordered by kinship and another society entirely ordered by market transactions. Consideration of either kind of fictitious society-the first perhaps the dream of early anthropologists and the second the dream of neo-liberals-supports the claim that relations of social subordination in our current society match neither social order. But if our society is not exclusively ordered by the market or by value patterns, then we need a social theory more complex than either 'culturalism' or 'economism' (2003b: 50-54).

${ }^{32}$ I say 'at least' here, because Fraser has repeatedly held out the promise, as a kind of promissory note, that her two-dimensional social theory may be expanded to a threedimensions, accounting for political ordering as an independent axis of social structure, with political exclusion as an independent harm, and political 'party' (following, again, Weber) as a third form of collectivity subject to parity-impeding dislocations. See, for instance, Fraser 2003b: 67-69. The need for a such a third political dimension in Fraser's theory has been compellingly articulated in Feldman 2002.

33 The language of Fraser's distinction, as well as her further mapping of a distinction between class-based groups and status-based groups onto the societal distinction, is obviously indebted to Weber.

${ }^{34}$ For sensitive discussions of such backlash effects in the United States context, see Fraser 1989, 1994.

35 See Honneth 2001: 52-53, and Honneth 2003b: 122-124 where the same charge that Fraser follows Taylor's history of movement types is leveled again.

${ }^{36}$ For an account of the usefulness of Honneth's distinction for understanding different kinds of feminist struggles as different kinds of recognition struggles, see Zurn 1997.

37 I expand on this criticism of Fraser's reading of Honneth in Zurn 2004.

38 Fraser consistently repeats this reduction of the broad concerns of Honneth's recognition theory to a narrow focus on an identity-based politics of difference: Fraser 2003b: 10; 2001: 31; 2001: 41, footnote 15 .

(C) Blackwell Publishing Ltd. 2005 
39 Putting Honneth's rejoinder to Fraser in legal terms also helps to highlight a deficiency evident in Fraser's theory: a lack of sustained attention to formal legal relations and political institutions. Honneth points out this deficiency Honneth 2003a: 251-252, but he himself has not yet provided a full analysis of legal structures and their relationship to mutual recognition relations.

40 This is, by now, a point familiar from the extensive recent literature on civil society, from Cohen and Arato 1992 to Varshney 2002. Striking throughout this literature is the lack of attention to Dewey's mature theory of democracy as a fruitful and suggestive progenitor. Honneth's work on Dewey is a welcome respite from this general theoretical trend.

${ }^{41}$ It should also be noted that this exclusivistic focus on the world of work as the privileged site for the development of self-esteem further exposes Honneth's general normative strategy to charges of a partialistic particularism masquerading as a form of universal, trans-contextual philosophical anthropology, charges I level and evaluate in Zurn 2000. For, is it really the case that undistorted self-realization is impossible in those socio-historic contexts without the careerist world of work as we currently know it in advanced capitalist societies?

${ }^{42}$ That each member of society ought to have an equal opportunity for social esteem follows from the general normative claim of each person to a recognition environment sufficient for an equal opportunity for full self-realization including healthy selfconfidence, self-respect, and self-esteem. In other words, the claim for distributive justice is here backed by the normative requirements for self-realization.

43 Americans with Disabilities Act of 1990 (ADA), 42 U.S.C. $\$ 12101$ et seq.

44 The love principle is realized in a society's specific forms of familial and intimate relations, and so is not, for Honneth, directly related to the prerequisites of capitalist markets. If my suggestion above about adequately socialized persons as functional requirements of markets is correct, however, then Honneth would have to extend his account of the normative principles underlying capitalism to include the love principle.

${ }^{45}$ Fraser and Honneth 2003b: 183, my translation. My thanks to Joel Anderson for help with this and the next translation. The corresponding passage in the English translation is at Honneth 2003b: 153-154.

${ }^{46}$ Fraser and Honneth 2003b: 285, my translation. The corresponding English passage is at Honneth 2003a: 248.

47 I say multi-valent since I am unconvinced that either Honneth's monistic framework, or Fraser's bi-valent framework is sufficient to analyze the structure and dynamics of legal forms of social ordering, especially as these interact with cultural and economic forms. This is, however, well beyond the reach of this paper.

48 An early version of some parts of this paper was given at The Conference on Democracy and Social Cohesion, sponsored by Tilburg University in Amsterdam, The Netherlands (September 1998). I would like to thank the participants for helpful comments, particularly those of Axel Honneth, comments that led me to abandon several of the central claims of that paper. I would also like to thank Kevin Olson, Vic Peterson, and an anonymous reviewer for helpful comments on earlier versions.

\section{REFERENCES}

Bohman, James (1998), 'Survey Article: The Coming of Age of Deliberative Democracy', The Journal of Political Philosophy 6(4): 400-425.

(c) Blackwell Publishing Ltd. 2005 
Cohen, Jean and Andrew, Arato (1992), Civil Society and Political Theory. Cambridge, MA: The MIT Press.

Dewey, John (1980), Democracy and Education. Carbondale: Southern Illinois University Press.

- (1984), The Public and Its Problems. Carbondale: Southern Illinois University Press.

Feldman, Leonard C (2002), 'Redistribution, Recognition, and the State: The Irreducibly Political Dimension of Injustice', Political Theory 30(3): 410-440.

Fraser, Nancy (1989), 'Women, Welfare, and the Politics of Need Interpretation', in Unruly Practices: Power, Discourse and Gender in Contemporary Social Theory, pp. 144-60. Minneapolis: University of Minnesota Press.

- (1994), 'After the Family Wage: A Postindustrial Thought Experiment', in Justice Interruptus: Critical Reflections on the 'Postsocialist' Condition, pp. 41-66. New York: Routledge.

- (1995), 'Recognition or Redistribution? A Critical Reading of Iris Young's Justice and the Politics of Difference', The Journal of Political Philosophy 3(2): 166-180.

- (1997a), 'From Redistribution to Recognition? Dilemmas of Justice in a 'Postsocialist' Age', in Justice Interruptus: Critical Reflections on the 'Postsocialist' Condition, pp. 11-40. New York: Routledge.

— (1997b), 'Heterosexism, Misrecognition, and Capitalism: A Response to Judith Butler', Social Text 15(3 and 4): 140-150.

— (1997c), 'Introduction: Justice Interruptus', in Justice Interruptus: Critical Reflections on the 'Postsocialist' Condition, pp 1-8. New York: Routledge.

_ (1997d), Justice Interruptus: Critical Reflections on the 'Postsocialist' Condition. New York: Routledge.

_ (1998), 'Social Justice in the Age of Identity Politics: Redistribution, Recognition, and Participation', in The Tanner Lectures on Human Values, edited by G. B. Peterson, pp. 1-67. Salt Lake City: University of Utah Press.

- (2000), 'Rethinking Recognition', New Left Review, (3): 107-120.

- (2001), 'Recognition without Ethics?', Theory, Culture \& Society 18(2-3): 21-42.

- (2003a), 'Distorted Beyond All Recognition: A Rejoinder to Axel Honneth', in Redistribution or Recognition? A Political-Philosophical Exchange, pp. 198-236. New York: Verso.

- (2003b), 'Social Justice in the Age of Identity Politics: Redistribution, Recognition, and Participation', in Redistribution or Recognition? A Political-Philosophical Exchange, pp. 7-109. New York: Verso.

Fraser, Nancy and Axel Honneth (2003a), Redistribution or Recognition? A PoliticalPhilosophical Exchange. New York: Verso.

— (2003b), Umverteilung oder Anerkennung: Eine politisch-philosophische Kontroverse. Frankfurt am Main: Suhrkamp Verlag.

Gitlin, Todd (1995), The Twilight of Common Dreams: Why America is Wracked by Culture Wars. New York: Metropolitan Books.

Habermas, Jürgen (1979), 'Historical Materialism and the Development of Normative Structures', in Communication and the Evolution of Society, pp. 95-129. Boston: Beacon Press.

— (1987), The Theory of Communicative Action. Volume 2: Lifeworld and System: A Critique of Functionalist Reason. Boston: Beacon Press.

— (1992), 'Individuation through Socialization: On George Herbert Mead's Theory of Subjectivity', in Postmetaphysical Thinking: Philosophical Essays, pp. 149-204. Cambridge, MA: The MIT Press.

C) Blackwell Publishing Ltd. 2005 
(1996), Between Facts and Norms: Contributions to a Discourse Theory of Law and Democracy. Cambridge, MA: The MIT Press.

Honneth, Axel (1979), 'Communication and Reconciliation: Habermas' Critique of Adorno', Telos, (39): 45-61.

(1992), 'Integrity and Disrespect: Principles of a Conception of Morality Based on the Theory of Recognition', Political Theory 20(2): 187-201.

- (1994), 'The Social Dynamics of Disrespect: On the Location of Critical Theory Today', Constellations 1(2): 255-269.

- (1995a), 'From Adorno to Habermas: On the Transformation of Critical Social Theory', in The Fragmented World of the Social: Essays in Social and Political Philosophy, pp. 92-120. Albany, NY: SUNY Press.

(1995b), 'Moral Consciousness and Class Domination: Some Problems in the Analysis of Hidden Morality', in The Fragmented World of the Social: Essays in Social and Political Philosophy, pp. 205-219. Albany, NY: SUNY Press.

- (1995c), The Struggle for Recognition: The Moral Grammar of Social Conflicts. Cambridge, MA: Polity Press.

(1995d), 'Work and Instrumental Action: On the Normative Basis of Critical Theory', in The Fragmented World of the Social: Essays in Social and Political Philosophy, pp. 15-49.

Albany, NY: SUNY Press.

(1996), 'Pathologies of the Social: The Past and Present of Social Philosophy', in

Handbook of Critical Theory, edited by D. M. Rasmussen, pp. 369-396. Cambridge, MA: Blackwell.

- (1998), 'Democracy as Reflexive Cooperation: John Dewey and the Theory of Democracy Today', Political Theory 26(6): 763-783.

- (2001), 'Recognition or Redistribution? Changing Perspectives on the Moral Order of Society', Theory, Culture \& Society 18(2-3): 43-55.

- (2003a), 'The Point of Recognition: A Rejoinder to the Rejoinder', in Redistribution or Recognition? A Political-Philosophical Exchange, pp. 237-267. New York: Verso.

- (2003b), 'Redistribution as Recognition: A Response to Nancy Fraser', in Redistribution or Recognition? A Political-Philosophical Exchange, pp. 110-197. New York: Verso.

Marsh, James L. (1995), Critique, Action, and Liberation. Albany, NY: State University of New York Press.

Olson, Kevin (2001), 'Distributive Justice and the Politics of Difference', Critical Horizons 2(1): 5-32.

Rawls, John (1996), Political Liberalism. New York: Columbia University Press.

— (1999), A Theory of Justice. Cambridge, MA: Harvard University Press.

Taylor, Charles (1989), Sources of the Self: The Making of the Modern Identity. Cambridge, MA: Harvard University Press.

(1992a), The Ethics of Authenticity. Cambridge, MA: Harvard University Press.

- (1992b), 'The Politics of Recognition', in Multiculturalism and 'The Politics of Recognition', pp. 25-73. Princeton, NJ: Princeton University Press.

Varshney, Ashutosh (2002), Ethnic Conflict and Civic Life: Hindus and Muslims in India. New Haven, CT: Yale University Press.

Weber, Max (1946), From Max Weber: Essays in Sociology. New York: Oxford University Press.

Zurn, Christopher F. (1997), 'The Normative Claims of Three Types of Feminist Struggles for Recognition', Philosophy Today 41(Supplement): 73-78.

(c) Blackwell Publishing Ltd. 2005 
(2000), 'Anthropology and Normativity: A Critique of Axel Honneth's "Formal Conception of Ethical Life"', Philosophy \& Social Criticism 26(1): 115-124.

(2003a), 'Arguing Over Participatory Parity: On Nancy Fraser's Conception of Social Justice', Philosophy Today 47(Supplement): 130-144.

(2003b), 'Identity or Status? Struggles over "Recognition" in Fraser, Honneth, and Taylor', Constellations 10(4): 519-537.

— (2004), 'Group Balkanization or Societal Homogenization: Is There a Dilemma between Recognition and Distribution Struggles?', Public Affairs Quarterly 18(2): 159-186. 